\title{
Model of Human Resource Development according to Iddhipada IV Principle of Educational Institutions under Office of Primary Educational Service Area
}

\author{
Phrakhruthammasarakosol (Samonrsak Dhammasantiko) ${ }^{1}$,Phrakhrusangharak Chakkit \\ Bhuripanyo $^{2}$, Peravat Chaisuk ${ }^{3}$, Thongdee Sritragarn ${ }^{4}$ \\ $1,2,3,4$ Faculty of Education, Mahachulalongkornrajavidyalaya University \\ 1,2 dews280@ hotmail.co.th, ${ }^{3}$ pchaisuk@gmail.com ${ }^{4}$ thongdee.sri@mcu.ac.th
}

\begin{abstract}
The purposes of this research were 1) to study the problem of human resource development according to Iddhipada IV principle of educational institutions under the Primary Educational Service Area Office, 2) to develop a model of human resource development according to Iddhipada IV principles of educational institutions under the Primary Educational Service Area Office, and 3) to propose a model of human resource development according to Iddhipada IV principles of educational institutions under the Primary Educational Service Area Office. Mixed methods research was used for research design. Quantitative data were collected from 103 samples, and was analyzed by using descriptive statistics. Qualitative data were collected by interview 10 key informants and focus group discussion with 10 experts, and data was analyzed by content analysis. Results showed that 1) the problem of human resource development according to Iddhipada IV principle of educational institutions under the Primary Educational Service Area Office found that the condition of human resource development must take into account the ideology and human resource development. This was an important principle of human resource development according to Iddhipada IV principle of educational institutions and analyzing data from respondents giving importance to the overall at high level. 2) A model of human resource development according to Iddhipada IV principle of educational institutions consisted of 1) human resource development through education, 2) human resource development through training, 3) human resource development by self-development, and 4) the principles that promote human resource development which were 1) satisfaction, 2) persistence, 3) attention, and 4) observation. 3) Model of human resource development according to Iddhipada IV principle of educational institutions under the Primary Education Service Area Office consisted of 1) use education as a basis for developing fit and sufficiency create love and satisfaction with work, 2) training and promoting activities to make efforts practice in performing duties, 3) being attentive to the assigned duties, and 4) being a person who adheres to reasons, physical development, mental development and intellectual development, and getting the trend of human resource development towards "Thailand 4.0".
\end{abstract}

Keywords

Human Resource Development, Iddhipada IV Principle,Primary Educational Service Area

Article Received: 10 August 2020, Revised: 25 October 2020, Accepted: 18 November 2020

\section{Introduction}

Human resource development can be considered as a valuable factor and it is very important to the organization because human resources help the organization to be successful in various fields. Human resource is a vital force that helps the organization achieve its intended objectives. Human resource development is the starting point for good human resource development, which is to educate people in all forms. It is not limited to studying in schools or universities only, and another way that an agency or organization. It is often used in development to enhance knowledge and skills. Academic aspects for personnel in departments or organizations is that providing education in the form of training is very important to the development of human resources.

Saman Rangsiyodrit, [1] said that human resource development should be aware of the importance of human resource development, and to develop individual potential especially the new generation of government officials. This is related to the concept of Saman Rangsiyodrit, [2] saying that personal development means taking action to promote people to have better knowledge, abilities, work skills, as well as to have a positive work attitude, work more efficiently, in other words, personal development is the process of enhancing and transforming practitioners in areas such as knowledge, abilities, skills, habits, attitudes, and methods of work that lead to productivity.

The administrators of the educational institution should seek an approach that can be integrated between the management system to be efficient, balanced and consistent in work properly and perfect with the use of management principles that are integrated with Buddhist principles. It is imperative to apply the principles of Buddhism to human resource management at the same time to achieve efficiency and effectiveness in human resource development which in Buddhism there are principles and teachings that can be applied and create incentives for personnel. This causes cooperation and cooperation in the work to be successful, which is the power of Iddhipada IV principle because it is considered a principle that makes the personnel in the organization have the determination and perseverance in the work that must face problems by finding reasons to fix problems to pass well by using the Iddhipada IV principles of power, I am willing to work, persistence, ready to work in accordance with the Chitta work plan; to guide human resource development of educational institutions under the Primary Educational Service Area Office and other educational institutions. 


\section{Research Objectives}

The purposes of this research were 1) to study the problem of human resource development according to Iddhipada IV principle of educational institutions under the Primary Educational Service Area Office, 2) to develop a model of human resource development according to Iddhipada IV principles of educational institutions under the Primary Educational Service Area Office, and 3) to propose a model of human resource development according to Iddhipada IV principles of educational institutions under the Primary Educational Service Area Office.

\section{Conceptual Framework}

The model of human resource development according to Iddhipada IV principles of educational institutions under the Primary Educational Service Area Office can be written as a research conceptual framework as in Fig.1.

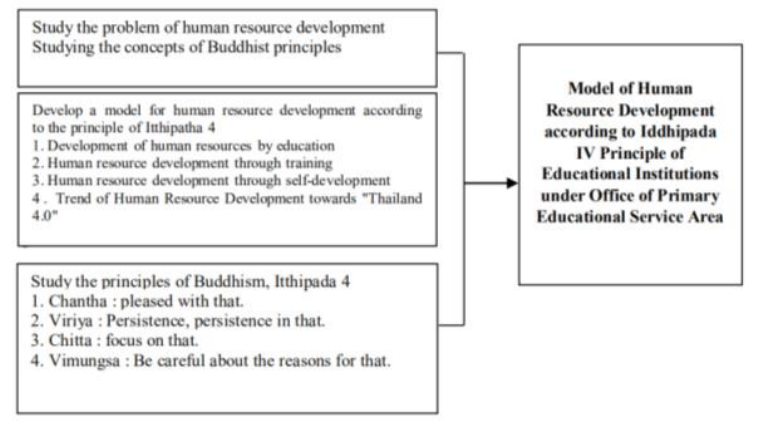

Fig.1 Conceptual Framework

\section{Research Method}

Mixed methods research was used for research design. Quantitative data were collected from 103 samples, and was analyzed by using descriptive statistics. Qualitative data were collected by interview 10 key informants and focus group discussion with 10 experts, and data was analyzed by content analysis, details were as the following research design.

\section{Data collection}

Data collection is divided into 2 steps 1) qualitative data, teacher management interviews, small group discussions from experts with administrative expertise. Buddhism, and quantitative data from the inquire received from the sample.

\section{Data analysis}

The data analysis process is divided as follows:

1) Qualitative data analysis from in-depth interviews with stakeholders. Collect qualitative data from interviews, to classify and organize information (Typology and Taxonomy).

2) Qualitative data from focus group discussion by using content analysis by examining and interpreting and make a conclusion from the information gathered.
3) Quantitative data were analyzed general information of the sample by descriptive statistics and percentage, mean, and standard deviation.

\section{Research Findings}

1. The condition of development according to the principle of achievement Iddhipada IV of the personnel in the educational institution under the Primary Education Service Area Office 1, by developing human resources according to the principle of influence Iddhipada IV of the school, thus creating the quality of life and society, integrating with the balance between wisdom, morality and culture, aiming to create a good foundation of society. School Administration must adhere to government regulations set by the Ministry of Education. It must adhere to the principles of good governance, namely "rule of law, morality, transparency principle, principle of participation, responsibility, and the principle of value "for virtue which is one of the important principles. It is important to human resource management and development. It is the achievement or the success of the work, which "the Buddha said about the power of Iddhipada IV that it is fair to help achieve success in work. If using the right four powers, the results will be effective." In the development of that country, the key is people at the center of the development of the economic development plan, and national society Therefore, people as the center of development give priority to providing opportunities for all sectors to join in developing the country.

It also gives importance to the development of the bureaucracy and civil servants by adhering to the principles of good governance for the administration of that educational institution school administrators must use the principles of good governance. One of the most important principles of good governance is virtue, which in Buddhism describes the principle of success, or the practice of Dharma according to the principles that will lead to success in the business is called the ideology (Dharma for success), which has 4 points: Chantha, Viriya, Chitta, and Vimangsa, and as a principle of occupation from the focus of the National Economic and Social Development Plan, it can be summarized as an idea that if the school administrators apply the principle of influence Iddhipada IV to the administration in the school will make various tasks in the scope of the educational institution administration has been achieved very well.

2. Develop a model of human resource development according to Iddhipada IV principles of educational institutions under the Primary Educational Service Area Office.

1) Human resource development through education, it is the most important factor for corporate development to national development. In order to create quality human resources in society, one of the important factors is education.

2) Human resource development through training is at the heart of human resource development today. This is an important part of the personnel to have knowledge, understanding, skills and attitudes in their operations until a change in operating behavior in the desired direction.

3) Human resource development through self-development to create productive and complete in a person's life there are many approaches and concepts. The main principles are 
summarized in 3 ways: medical self-development, psychological self-development, and Buddhist development using the Buddhist principles of Buddhism.

4) Self-development according to the Buddhist principles and the promotion of a model approach to the development of characteristics of influence Iddhipada IV principles for the personnel in the educational institution (1) I am satisfied and love for it, (2) persistence, persistence in that perseverance, and persistence to do the best work or do something, (3) Chitta, focus on it, (4) Insight on the persistence of its reasoning, to research, experiment, invent, and think, keep improving work to keep progress.

3. The human resource development model according to the Iddhipada IV principles under the Office of the Primary Education Area in 4 forms:

1. Personal Development, use desire, satisfaction, and affection as a guideline for human resource development.

2. Training requires persistence and persistence sent to train with various activities.

3. Medical Self-development psychological self-development takes care of mind all the time.

4. Recognize, research, experiment, innovate and think, modify, improve work to keep progress by using wisdom, diligence in reason.

When considering the model of person development according to the principle of influence Iddhipada IV principles of educational institutions under the Primary Educational Service Area Office Overall and the categories were classified by gender, age, education level, occupation, income and overall working period at a high level. When considering on a case-by-side basis, it was found that the sample group studied had a pattern of person development according to the principle of influence Iddhipada IV principles at a high level in all 4 issues:

1. I am pleased with that.

2. Persistence, persistence in that.

3. Chitta, attention, focus on that.

4. Witness the observance of the reasons for that.

All 4 issues studied qualitatively and analyzed for consistency in question from questionnaires about Buddhism principles on development. The sample group used Buddhist principles on the development of the person development model according to the principle of succession Iddhipada IV of educational institutions under the Primary Educational Service Area Office. Overall, it was found to be of great importance. The mean of 4.28 and the standard deviation of 0.24 . It was found that all aspects were of great importance, including the mean of 4.34 and the standard deviation of 0.28 , the persistence side had the mean of 4.22 and the standard deviation of 0.35 , the Chitta side had the mean of 4.30 and the deviation. The standard deviation is 0.37 , the Vimangsa side has the mean of 4.37 and the standard deviation of 0.34 , respectively, to support. "Human Resource Development Model according to the Principle of Iddhipada IV under the Primary Educational Service Area Office", the results of statistical data analysis.

\section{Discussions}

1. The problem of human resource development according to Iddhipada IV principles of educational institutions under the Primary Educational Service Area Office.
The administration of educational institutions must adhere to the government regulations set by the Ministry of Education. It must adhere to the principles of good governance, namely "rule of law, morality, transparency principle. Principle of participation responsibility and the value principle "in the development of that country. The key is people at the center of the development of the economic development plan and national society. Therefore, people as the center of development give priority to providing opportunities for all sectors to join in developing the country. This is in line with the research of Theerawat Charoenphon and others [4] who have studied the application of the principle of virtue of Dhamma in the performance of government officials and Officials of Lan Saka District Office, Lan Saka District, Nakhon Si Thammarat Province.

1) Government officials and officials, the principle of virtue of Dharma was applied in the performance of the Lan Saka District Office, Lan Saka District, Nakhon Si Thammarat Province, in all four aspects at a high level. Considered side by side, sorted by average, it was found that the aspect of self-determination, performance satisfaction, was the most followed by Vimangsa, the use of wisdom and reasoning in the performance. In terms of persistence, work persistence was the lowest, respectively, when classified by sex, age, education level, status and monthly income found that overall was at a high level.

2) Comparison results application of the principle of virtue of Dharma in the work of government officials and officials at Lan Saka District Office, Lan Saka District, Nakhon Si Thammarat Province with different sex, age, education level, status and monthly income. Overall, there was no significant difference at the .05 level.

3) Suggestions on problems and ways to promote the use of the principle of virtue in the work at Lan Saka District Office, Lan Saka District, Nakhon Si Thammarat Province, such as persistence, perseverance in the work is the amount of work that is too much to be able to operate meeting the deadline as for the suggestions on how to promote the implementation of the principle of virtue, the principle of persistence, perseverance in the work is to assign duties across all sectors. [5]

2. Develop a model of human resource development according to Iddhipada IV principles of educational institutions under the Primary Educational Service Area Office.

How to create a reflection on your work, think about the good and the bad that will happen, and should be able to study operational procedures to understand and clearly know the scope of work. When analyzing research results, it was found that it was consistent with [6] that aimed to study the level and compare the use of the Iddhipada IV influence to be used in the work of the employees of Phuket Air Traffic Control Center Aeronautical Radio of Thailand Limited according to the history of training and to know the methods and suggestions for implementing the power of Iddhipada IV to be used in the work the target population is 98 Phuket Air Traffic Control Center employees, estimate scale type questionnaires, observations and interviews. The statistics used for data analysis were percentage, mean, standard deviation, and hypothesis using t-test. 
1. Utilizing Iddhipada IV to be used in the work of employees of Phuket Air Traffic Control Center overall and each component is at a high level.

2. Staff of Phuket Air Traffic Control Center with different training history, there is an influence of Iddhipada IV to be used in the work as a whole and each element is not different.

3. The staff of Phuket Airline Control Center has applied the power of Iddhipada IV to their work successfully through external motivation. And use the influence of Iddhipada IV more and less depending on the nature of the work. The way of implementing the power of 4 is to create an ambition to arise in one's mind first in order to achieve passion or desire to do that task in order to achieve that goal. While working, Chitta must be willing or attentive and responsible for the work performed. In order to get good results with quality and finally, Vimangsa is required to think carefully and reflect on the work done. There is an investigation of any defects from the operation and find solutions for improvement in the future to ensure the best performance and there are suggestions for bringing the power.

4. To be used in the work of the staff of Phuket Airline Control, that is, in every work, you should be satisfied to like that job in order to be happy and have fun at work. The supervisor should delegate the work to match the competence of the employee should be diligent, not discouraged by obstacles are enthusiastic about working that have the intention and pay attention to the work should always study and learn more, work methods should be improved to be more efficient and should work together as a team. In addition, the development of human resources in the 4.0 era, technology has progressed greatly. Things around us are changing rapidly from the adoption of technology to the trend of "Thailand 4.0" aimed at restructuring the economy to the "economy driven by innovation" has an impact both at the individual and organizational levels. Whether it is the service industry or education, the development of technology is leapfrogging wireless connections narrow the world. People's lifestyles have changed from the original, change all around both economic, social, political and environmental aspects volatile and unpredictable conditions are the driving force behind the intensifying business competition.

3. Propose a model for human resource development according to the principle of Iddhipada IV, under the Primary Educational Service Area Office.

Human resource development, it is essential for the development of the organization and the nation. One of the main drivers of that development is education. In addition to the foundation that has been implanted, the development of education in the working age is considered important as well became a competent human resource throughout until having the potential for performance will help to develop the work even better or cause adjustments and changes or become a new working system that blocks the leakage of defects.

Human resource development according to the principle of succession Iddhipada IV should be developed in a Buddhistintegrated way the principle of Buddhism is a development tool, there are Iddhipada IV principle forms: 1) Develop human resources by education, focus on feeling and changing attitudes about education, satisfaction and affection for that, lay the foundation of life through education. 2) Human resource development through training, using activities whether it is training or organize activities to promote potential development both learning Work and social life Focus on training, perseverance, patience, determination for success 3) Human resource development through self-development. 4) Trends in human resource development towards "Thailand 4.0" to promote integrated Buddhist development between Western theory and development. Buddhist principles It is called the development of the body and mind, namely the physical, mental and intellectual.

Presentation of the Human Resource Development Model according to the Principle of Iddhipada IV under the Primary Educational Service Area Office by synthesizing qualitative information on the issues studied developed as a questionnaire using the principle of influence on each question which is related to the promotion of development. It was found that the development of the person development model according to the Iddhipada IV principles of the educational institution under the Primary Educational Service Area Office. Overall, it was found that the significance was at a high level (Mean= 4.28, S.D. $=0.24)$. It was found that all aspects were of great importance, which consisted of chit $(\mathrm{Mean}=4.34, \mathrm{SD}=0.28)$, persistence $(\mathrm{Mean}=4.22, \mathrm{SD}=0.35)$, Chitta $(\mathrm{Mean}=4.30, \mathrm{SD}=0.37)$, Vimangsa $($ Mean $=4.37, \mathrm{SD}=0.34)$, respectively, the analysis results were consistent with the research work of Katiya Ayu-Yuen on research title human resource development through Buddhist principles for sustainable organization development [7].

\section{Body Of Knowledge From Research}

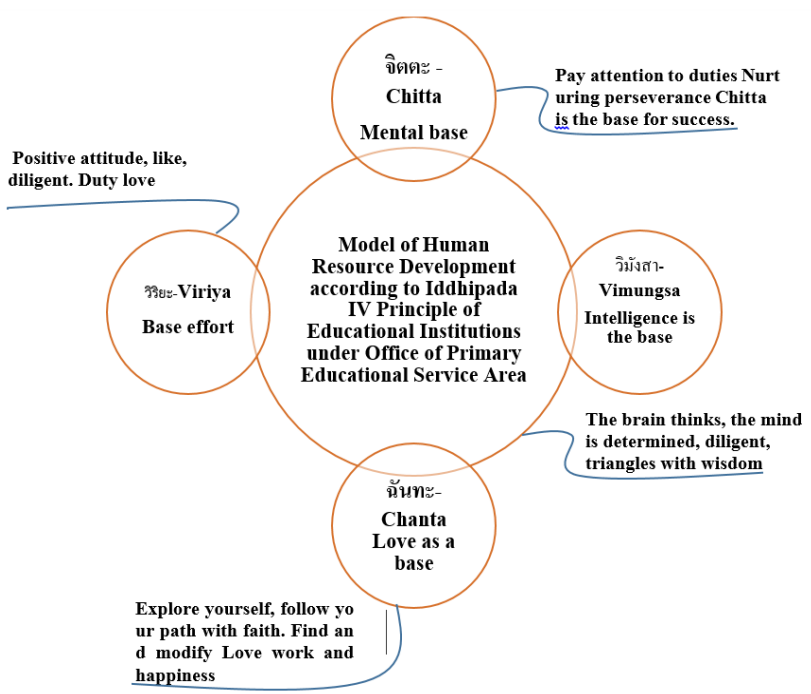

Fig. 2 Model of Human Resource Development according to Iddhipada IV Principle of Educational Institutions under Office of Primary Educational Service Area

Presentation of the Human Resource Development Model according to the Principle of Iddhipada IV [8] under the Primary Educational Service Area Office and analyzed the participation in applying principles related to promoting development by starting to study the condition of the characteristics of the power of Iddhipada IV principle of the personnel in the education under the Primary Educational 
Service Area Office and guidelines for the development of traits of Iddhipada IV for personnel According to the Buddhist principles of education administration by integrating with relevant Buddhist principles. This resulted in a model of human resource development according to the principle of the Iddhipada IV principle of educational institutions under the Primary Educational Service Area Office, and integrate into the schools of interest in the future. The key to creating a model of human resource development based on the principle of the Iddhipada IV is the integration of the Iddhipada IV principle with the resource development model in the characteristic condition, namely human resource development through education, human resource development through training, human resource development through self-development. The trend of human resource development towards "Thailand 4.0" [9] with Buddhist principles and the promotion of approaches, the development model of the Iddhipada IV principles traits, namely: I am contentment, affection, persistence, persistence in that, Chitta, attention to that to be careful of the reasons for that which this body of knowledge obtained from research studies on this subject and should present to integrate with educational institutions in the future.

\section{Recommendations}

\section{Recommendation for policy}

1) Government agencies or departments related to education management or the Ministry of Human Resource Development Human resource development should be promoted by educational personnel should be encouraged to continue their studies by requesting regular working hours, or part time working and support further study by providing some scholarships to increase work potential.

2) Training by relevant departments, human resource development through training and training should focus on their participation to improve work methods for maximum results, creating interest and satisfaction in work performance for personnel.

\section{Recommendation for further research}

1) The research results should be used in the study of the human resource development model according to the principles. It is the Iddhipada IV principles of educational institutions under the Primary Education Service Area Office to adapt to the application with other departments or educational institutions and study the effectiveness of w3management and work of personnel.

2) It should study the development of personnel competencies in public universities with an emphasis on human resource development with emphasis on other Buddhist of human resource development model according to Itthipada IV principle [10] under the Primary Educational Service Area Office and analyzed the participation in applying principles related to promoting development by starting to study the condition of the characteristics of the power of Iddhipada IV principles of the personnel in the education under the Primary Educational Service Area Office and guidelines for the development of traits of Iddhipada IV principles for personnel. According to the Buddhist principles of education administration by integrating with relevant Buddhist principles resulting in a model of human resource development according to the Iddhipada IV principles of educational institutions under the Primary Educational Service Area Office and integrate into the schools of interest in the future. The key to creating a model of human resource development based on the principle of the Itthipada IV is the integration of the Iddhipada IV principles with the resource development model in the characteristic condition, namely human resource development through education. Human resource development through training Human resource development through self-development. The trend of human resource development towards "Thailand 4.0" [11] with Buddhist principles and the promotion of approaches, the development model of the Iddhipada IV principles traits, namely: I am contentment, affection, persistence in that, Chitta, [12] attention to that to be careful of the reasons for that which this body of knowledge obtained from research studies on this subject and should present to integrate with educational institutions in the future [13].

\section{References}

[1] S. Rangsiyokrit. General knowledge about personnel management, 13th edition. Bangkok Welfare Office, 1987.

[2] S. Rangsiyokrit, General knowledge about personnel management, 13th edition, Bangkok Welfare Office, 1987.

[3] T. Sinjaru. Research and analysis of statistical data with SPSS, 9th edition, Bangkok: S.R. Printing Mass Products, 2008.

[4] T. Charoenphol et al, Applying the principle of virtue of Dharma to the performance of government officials Official at Lan Saka District Office, Lan Saka District, Nakhon Si Thammarat Province, Journal of Buddhist Sociology, Periscope Journal of Buddhist Sociology, Vol. 3, Issue 1 (January-June 2018).

[5] B. Boon-iam. Research report, studies on the use of Iddhipada IV in the work of the employees of the Phuket Air Force Center, Aeronautical Radio of Thailand Ltd. Aeronautical Radio of Thailand Ltd., 2011.

[6] K. Ayu-Yuen, Human Resource Development Through Buddhist Principles for Sustainable Organization Development, Thammathat Journal Vol. 16, No. 2 (July - October 2016). 
[7] Phra Promkhunaporn (P.A. Piyutto), Creating wisdom for the future of humanity, 7th edition, Bangkok: Saha Thamik Company Limited, 1997.

[8] P. Sukonthachit. Human Resources 4.0, NKRAFA Journal of Humanities and Social Sciences, Year 7 December 2019.

[9] Phra Dharmakosajarn, (Prayoon Dhammajitto), Buddhism and Philosophy. Bangkok: Arin Printing Group, 1990.

[10] S. Thongkerd, Research report on human resource management in the era of Thailand 4.0, 2017.

[11] Buddhadasa Bhikkhu (Ngam Inthaphan), Objectives of education, Bangkok: Nirvana Publishing House, 1994

[12] A. Panthasen. Buddhism: Evolution, Theory, and Its Applications to Economics, Bangkok: Amarin Printing Press, 2001. 